\title{
Failure Predictions for Graphite Reflector Bricks in the Very High Temperature Reactor with the Prismatic Core Design
}

\author{
Gyanender Singh, Alex Fok and Susan Mantell
}

\begin{abstract}
Graphite is used in nuclear reactor cores as a neutron moderator, reflector and structural material. The dimensions and physical properties of graphite change when it is exposed to neutron irradiation. The non-uniform changes in the dimensions and physical properties lead to the build-up of stresses over the course of time in the core components. When the stresses reach the critical limit, i.e. the strength of the material, cracking occurs and ultimately the components fail. In this paper, an explicit crack modeling approach to predict the probability of failure of a VHTR prismatic reactor core reflector brick is presented. Firstly, a constitutive model for graphite is constructed and used to predict the stress distribution in the reflector brick under in-reactor conditions of high temperature and irradiation. Fracture simulations are performed as part of a Monte Carlo analysis to predict the probability of failure. Failure probability is determined based on two different criteria for defining failure time: A) crack initiation and B) crack extension to near control rod channel. A significant difference is found between the failure probabilities based on the two criteria. It is predicted that the reflector bricks will start cracking during the time range of 5-9 years, while breaching of the control rod channels will occur during the period of 11-16 years. The results show that, due to crack arrest, there is a significantly delay between crack initiation and breaching of the control rod channel.
\end{abstract}

\section{Introduction}

Nuclear energy systems are promising sources for meeting the rapidly increasing energy demands of the world population. The Very High Temperature Reactor (VHTR) [1] is one of the future reactor systems designed to be used for power generation and high-temperature process heat applications such as hydrogen fuel production. Due to its excellent mechanical and thermal properties, graphite is used in the VHTR core where it serves as a neutron moderator, reflector and structural material. When exposed to fast neutron irradiation, the graphite core components will undergo dimensional and physical property changes [2] which may restrict the movement of control rods through the core and produce failurecausing stresses that undermine the safe operation of the reactor. Thus, it is imperative to assess the structural integrity of the VHTR graphite components over the reactor's design lifetime.

Several researches have been conducted to assess the structural integrity of graphite bricks. Oku and Ishihara [3] considered two methods of assessment: one based on comparison of stresses with the strength of the graphite and the other based on dimensional changes in graphite. They suggested that the one that gave a shorter lifetime should be used. Yu et al. [4] used the finite element method to compute stresses in a HTR-10 (a test reactor of the pebble bed design) reflector brick and evaluated the failure probability using the Weibull model [5,6]. The dependence of physical properties such as thermal conductivity, thermal expansion coefficient, creep coefficient and elastic modulus on temperature and fast neutron dose was included in the finite element code. The failure probability was evaluated as a function 
of time under normal operating conditions as well as cold shutdown conditions. It was reported that the failure probability of the graphite brick after 20 years of operation was $2.3 \times 10^{-12}$ and $4.7 \times 10^{-11}$ under the two conditions, respectively. The constitutive law and the material properties used in the analysis for graphite were not provided in detail.

Li et al. [7] conducted an analytical study to evaluate the axial and hoop stresses in a hypothetical cylindrical moderator brick containing a fuel rod in the middle as a function of time. The effect of creep strain, dimensional change strain and elastic strain on the stresses was included. They confirmed that in the outer region of the brick the hoop and axial stresses were compressive initially but gradually turned tensile and continued to increase in magnitude with time. In the inner region of the brick, the stresses were tensile initially but gradually turned compressive and continued to increase in magnitude. The nature of the stresses (tensile/compressive) changed after a period of approximately 20 years.

Mechanical tests on an Advanced Gas-Cooled Reactor (AGR) graphite moderator brick were simulated by Zou et al. [8] using the commercial finite element software Abaqus. The failure process in the brick was predicted using a failure model based on continuum damage mechanics which was implemented in the software using the User Element Subroutine UEL [9]. The simulation results showed that fracture was characterized by the development of a damage zone and then a small crack at the keyway corner, followed by unstable propagation of the crack. The failure predictions were compared with the results from experimental tests and were found to be in good agreement. However, the work did not incorporate the complex reactor conditions and its effect on the graphite.

Tsang and Marsden [10] presented a constitutive model which described the thermo-mechanical behavior of graphite under irradiation. The model considered elastic strain, primary and secondary creep strains, thermal strain and dimensional change strain. Besides these strains, interaction thermal strain and interaction dimensional change strain that were caused by creep were also included in the model. The model was implemented as a User Material Subroutine (UMAT) in the finite element software Abaqus [9]. Using the model stresses were evaluated in a hypothetical graphite brick. A turnaround in the stresses (tensile to compressive and vice versa), as predicted by previous researchers, was observed. It was also found that there was a sharp increase in the magnitude of the stresses during reactor shutdown.

Mohanty et al. [11] developed a finite element code for performing coupled thermal-structural analysis of graphite core components under high temperature and irradiation conditions. The authors also used the user-subroutine feature of Abaqus to evaluate stresses in the core components. They presented some preliminary results of the stress analysis for a typical fuel brick in the General Atomics Gas Turbine-Modular Helium Reactor (GT-MHR) configuration. However, they did not consider failure of the brick.

The goal of the work presented herein is to predict the failure probability of VHTR reflector bricks of the prismatic design (Figs. 1 and 2). To predict the failure probability of brittle structures subjected to stresses, the Weibull model has been extensively used. But the model has its shortcomings, one of which is that the so-called Weibull modulus, which is considered a material property, actually depends on the specimen geometry and loading conditions [12]. Also, the Weibull model does not handle stress concentrations well, overestimating the probability of failure of brittle structures with high stress concentrations. 
As mentioned earlier, fracture in a non-irradiated AGR graphite moderator brick under mechanical loading was successfully predicted using continuum damage mechanics [8]. A recent study, which also employed a fracture-modeling approach, showed reasonable success in predicting the effect of size on the fracture properties and associated statistics of nuclear graphite [13]. Therefore, instead of using the Weibull model, explicit modeling of crack initiation and propagation in the graphite components was adopted in the work presented herein. The fracture simulations were performed as part of a Monte Carlo analysis to predict the probability of failure of VHTR graphite components.

The present work addresses the key research need for the development of constitutive models and failure models for graphite, with the long-term goal being to maximize the design life of the Next Generation Nuclear Plants (NGNP) [1], of which the VHTR is one of the candidates. The work also aims to decrease the uncertainties and design margins associated with the existing approaches, and to contribute to the current development of the ASME codes for the design and construction of VHTR core components.

\section{Methods}

In the work presented herein, a constitutive model for graphite was constructed and implemented in Abaqus through its user-defined subroutine UMAT to predict the stress distribution in a VHTR reflector brick. The UMAT subroutine was used in conjunction with Extended Finite Element Method (XFEM) to predict fracture of the reflector brick under in-reactor conditions of high temperature and irradiation. Monte Carlo analysis, which involved simulation of fracture in reflector bricks having randomly different properties, was performed to predict probability of failure as a function of time. The bricks were assumed to be made of ATR-2E graphite which was developed by the former company Sigri Elektrographit GambH as a reference material for future High-Temperature Reactors (HTR) [14] in the framework of Germany's former R\&D program "HTR with Spherical Fuel Elements". ATR-2E graphite was chosen because it had the complete set of property data required to perform the analysis at the time when this work was being carried out.

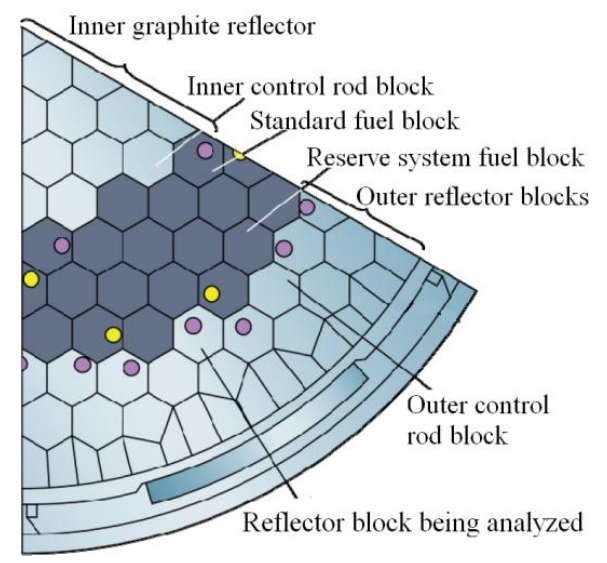

Figure 1: Location of prismatic reflector brick considered for failure analysis [15]. 


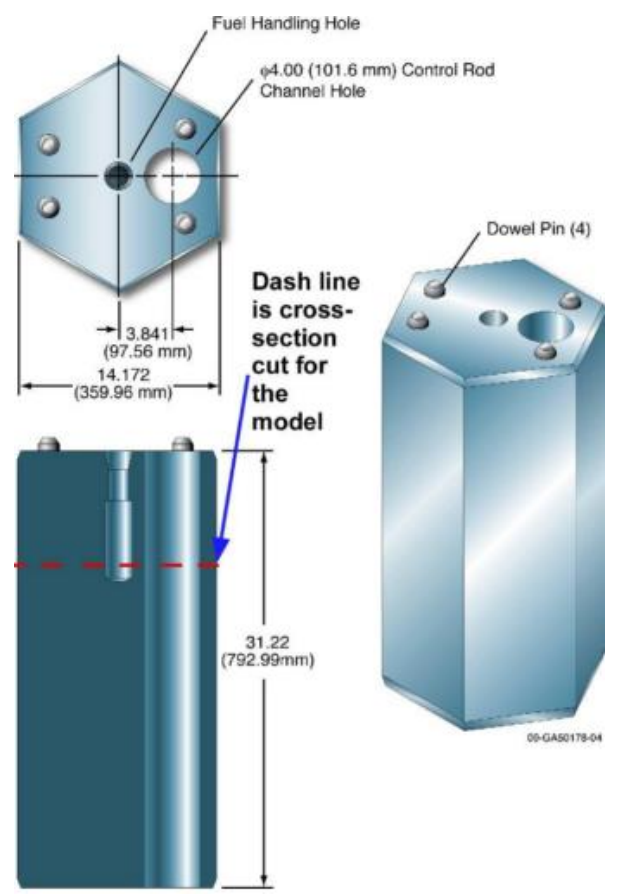

Figure 2: Dimensional details of prismatic reflector brick considered for failure analysis [15].

\subsection{Constitutive Model}

The net strain in irradiated graphite is constituted of several strain components. The strain corresponding to irradiation-induced dimensional change is called dimensional change strain $\left(\boldsymbol{\varepsilon}^{\mathrm{dc}}\right)$. Nonuniform dimensional change due to non-uniform irradiation causes elastic strains $\left(\boldsymbol{\varepsilon}^{e}\right)$ and stresses in a graphite component. These irradiation-induced stresses can be crept out by the irradiation itself. The irradiation creep strain $\left(\varepsilon^{\mathrm{c}}\right)$ has two components: primary $\left(\boldsymbol{\varepsilon}^{\mathrm{pc}}\right)$ and secondary $\left(\boldsymbol{\varepsilon}^{\mathrm{sc}}\right)$ creep strains. It can be expressed as:

$\varepsilon^{c}=\frac{a \sigma}{E_{o}}[1-\exp (-b \gamma)]+K \sigma \gamma$

where $\mathrm{a}$ and $\mathrm{b}$ are constants associated with primary creep, $\mathrm{E}_{\mathrm{o}}$ is the Young's modulus of virgin graphite, $\sigma$ is the stress, $\gamma$ is the neutron dose, $\mathrm{K}$ is the secondary creep coefficient [16]. The first term in equation (1) represents the primary creep strain $\left(\varepsilon^{\mathrm{pc}}\right)$ and the second term represents the secondary creep strain $\left(\varepsilon^{\mathrm{sc}}\right)$. For moderate to high dose levels, the primary creep strain is much smaller than the secondary creep strain. It was therefore neglected in the current analysis. Due to operational changes in the temperature and irradiation-induced changes in the thermal properties, graphite undergoes thermal expansion/contraction, resulting in thermal strains $\left(\boldsymbol{\varepsilon}^{\text {th }}\right)$. Thus, the total strain $\left(\varepsilon^{\text {total }}\right)$ of graphite is composed of the elastic strain, dimensional change strain, creep strain and thermal strain, i.e.

$\varepsilon^{\text {total }}=\varepsilon^{\mathrm{e}}+\varepsilon^{\mathrm{pc}}+\varepsilon^{\mathrm{sc}}+\varepsilon^{\mathrm{dc}}+\varepsilon^{\text {th }}$

The stresses $(\boldsymbol{\sigma})$ and their increments $(\Delta \boldsymbol{\sigma})$ are obtained using the elastic strain according to Hooke's law of linear elasticity:

$\boldsymbol{\sigma}=\mathbf{D} \boldsymbol{\varepsilon}^{\mathrm{e}}$ 
where $\mathbf{D}$ is the elastic stiffness matrix. Since the Young's modulus is dependent upon irradiation dose and temperature, $\mathbf{D}$ is also a function of dose and temperature. The dependence of the dimensional change strain, creep strain, thermal strain and physical properties on the temperature and neutron irradiation for the graphite under consideration were obtained from existing literature [14]. To evaluate the irradiationinduced stresses in the graphite brick, the constitutive model was implemented in Abaqus using its userdefined material subroutine (UMAT), which allowed the user to define the mechanical behavior of the material. To assess the accuracy of the stress predictions using the UMAT subroutine, the hypothetical cylindrical brick considered by $\mathrm{Li}$ et al. [7] analytically was first considered. Since the brick has symmetry about its long axis, only $1 / 8^{\text {th }}$ of the brick was considered to reduce the computational cost (see Figure 3).

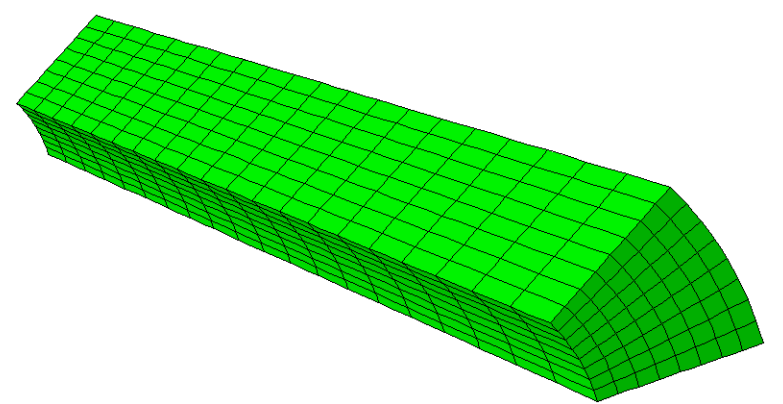

Figure 3: $1 / 8^{\text {th }}$ section of a hollow cylindrical graphite brick with fuel in the middle.

The cylindrical section model was meshed with C3D20 elements [9] which are 3D quadratic isoparametric elements with 20 nodes. The model contained 6345 nodes and 1280 elements. A thermal steady state condition was considered so the temperature was kept constant while the irradiation dose varied linearly with time $\left(199 \times 10^{20} \mathrm{n} / \mathrm{cm}^{2}\right.$ at the end of 30 years at the inner surface). The inner surface of the cylinder was exposed to a higher level of irradiation, which decreased linearly with an increase in the radial distance. Figure 4 shows the irradiation dose distribution in the brick at the end of 30 years.

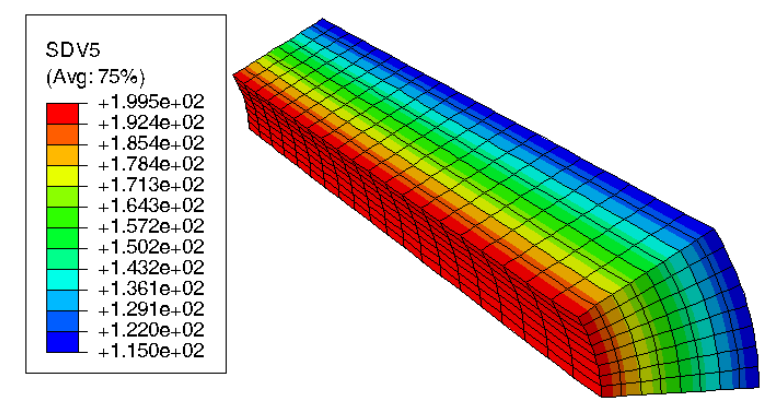

Figure 4: Irradiation dose $\left(10^{20} \mathrm{n} / \mathrm{m}^{2}\right)$ distribution in the graphite brick at the end of 30 years.

The primary creep strain was neglected as it was very small relative to the secondary creep strain. The numerical solution for the stresses in the cylinder was compared with the analytical solution in [7]. After establishing its accuracy, the UMAT subroutine was used to evaluate the stresses in the prismatic core reflector brick. 


\subsection{Crack Simulation and Statistical Analysis}

As discussed earlier, the Weibull model has its shortcomings: dependence of the Weibull modulus on the geometry of the structure and loading conditions, and overestimation of the failure probability for structures with stress concentrations. These shortcomings lead to inaccuracy in the failure predictions of the components. One of the ways to predict the probability of failure more accurately is by conducting explicit crack simulation combined with statistical analysis. In the work presented herein, the Extended Finite Element Method (XFEM) was employed to simulate cracking in the prismatic core reflector brick in order to obtain more accurate failure predictions. XFEM, developed by Belytschko et al. [17], is based on the unity partition function [18]. It allows the presence of discontinuities in an element by enriching it with special degrees of freedom which obviate the need to match the mesh with the geometry of the discontinuity. XFEM can be used to simulate crack initiation and propagation along an arbitrary, solution-dependent path without the need to re-mesh the model as the crack advances. This feature makes this technique an attractive choice for handling complex geometries and complex loading such as those for VHTR core components.

XFEM is combined with the UMAT subroutine for graphite on the common computational platform that is Abaqus to predict the failure of the prismatic core reflector brick under in-reactor conditions. The model was divided into a XFEM and a non-XFEM domain, as shown in Figure 5.

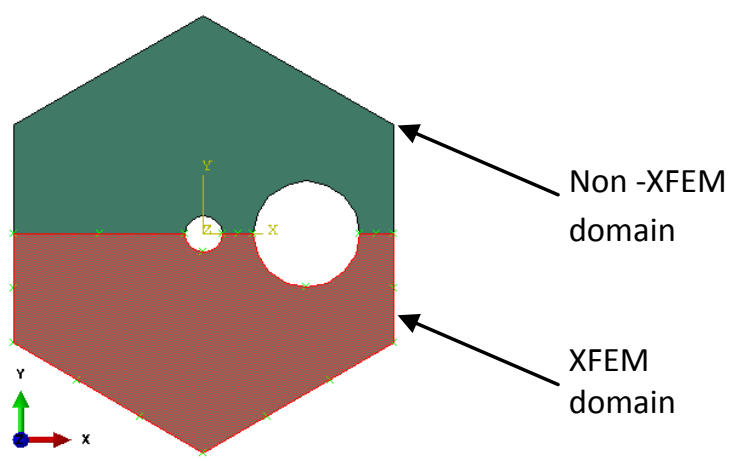

Figure 5: Brick model divided into enriched and non-enriched XFEM regions.

In the XFEM domain, the nodal degrees of freedom were enriched with special displacement functions to allow for the presence of discontinuities in the elements. The occurrence of cracking was thus limited to this region of the brick. This was to prevent symmetric double cracking in the brick model, which is unlikely to occur in reality due to material heterogeneity. The model was meshed with 3625 CPE4 (continuum, plane-strain, bilinear, 4-node) [9] elements with 3756 nodes, as shown in Figure 6. Figure 6 shows the boundary conditions. 


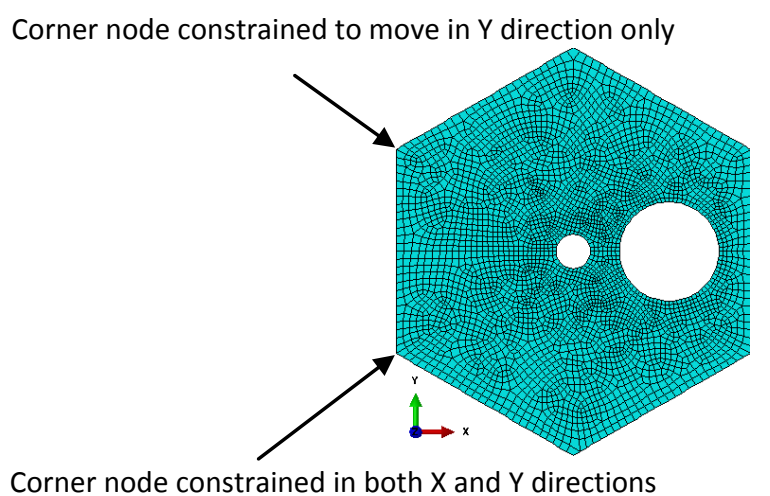

Figure 6: Brick meshed with CPE4 elements and applied boundary conditions.

The irradiation dose distribution (shown in Figure 7) was based on the operating conditions for a reflector brick in the Ft. St. Vrain reactor as presented in [10,19]. The reflector brick was considered to be surrounded by fuel bricks on three sides (right-top, right and right-bottom). A temperature distribution based also on the operating conditions of the Ft. St. Vrain reactor was used for the numerical analysis [19]. The temperature distribution used is shown in Figure 8 and was assumed to remain constant.

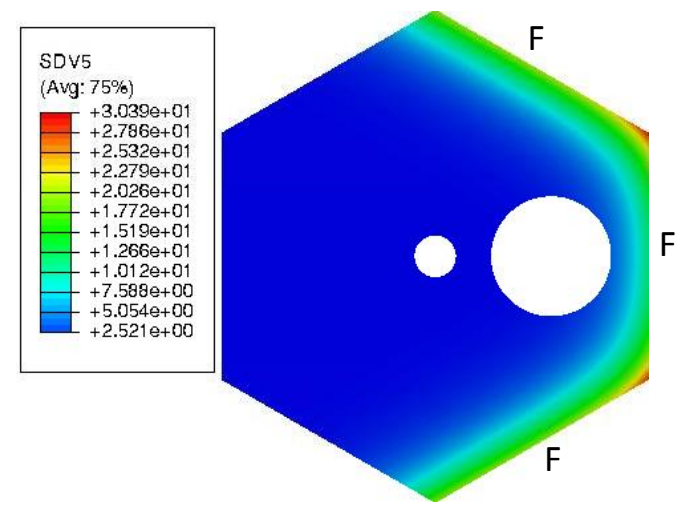

Figure 7: Irradiation dose distribution $\left(\times 10^{20} \mathrm{n} / \mathrm{cm}^{2}\right)$ in the prismatic reactor core brick at the end of 6 years. ' $\mathrm{F}$ ' indicates boundary with fuel brick.

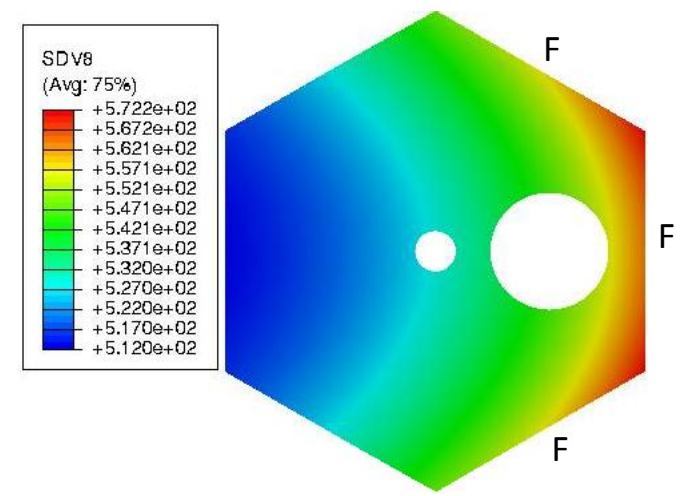

Figure 8: Temperature distribution in the prismatic reactor core brick. ' $\mathrm{F}$ ' indicates boundary with fuel brick. 
The material properties for ATR-2E graphite were based on the work conducted by Haag [14]. These properties included the variations of dimensional change strain, coefficient of thermal expansion and Young's modulus with dose and temperature. The irradiation-induced creep was assumed to follow the U.K. creep law [16] and the creep modulus was considered to be constant. The exact failure law for ATR-2E is not known. Since graphite is a quasi-brittle material the maximum principal stress criterion was selected as the damage initiation criterion. Zhou et al. [8] has successfully employed a damage evolution law with tension softening to predict crack initiation and propagation in Gilsocarbon graphite bricks. Therefore, for simplicity, a damage evolution law based on the critical fracture energy and a linear softening law was selected in this work. The critical fracture energy $\left(\mathrm{G}_{\mathrm{IC}}\right)$ was calculated from the stress intensity factor $\mathrm{K}_{\mathrm{IC}}$ using the Irwin relationship as follows:

$G=\frac{K^{2}}{E}\left(1-v^{2}\right)$

where $v$ and E are Poisson's ratio and Young's modulus, respectively. The variation of the fracture energy and strength with irradiation was not considered. The mean values for the strength and critical stress intensity factor for ATR-2E graphite were assumed to be $12.5 \mathrm{MPa}$ and $1.0 \mathrm{MPa} \sqrt{\mathrm{m}}$, respectively. The reactor was considered to be in operation for 30 years.

The statistical analysis of the failure of the ATR-2E reflector brick was performed using the Monte Carlo method. Thirty specimens of the reflector brick, each having a randomly different set of strength and fracture toughness values, were modeled. The different values of the strength $\left(\sigma_{f}\right)$ and critical stress intensity factor $\left(\mathrm{K}_{\mathrm{IC}}\right)$, based on the Weibull distribution, were generated randomly using MATLAB. The mean values and the assumed corresponding Weibull modulus of $\sigma_{f}$ and $K_{I C}$ used for ATR-2E graphite are shown in Table $1[13,14]$.

Table 1: The mean value and Weibull modulus for strength and critical stress intensity factor for ATR-2E graphite [13,14].

\begin{tabular}{|c|c|c|}
\cline { 2 - 3 } \multicolumn{1}{c|}{} & $\begin{array}{c}\text { Mean } \\
\text { value }\end{array}$ & $\begin{array}{c}\text { Weibull } \\
\text { modulus }\end{array}$ \\
\hline Strength $\left(\boldsymbol{\sigma}_{\mathbf{f}}\right)$ & $12.5 \mathrm{MPa}$ & 9 \\
\hline $\begin{array}{c}\text { Critical stress } \\
\text { intensity factor }\left(\mathbf{K}_{\mathbf{I C}}\right)\end{array}$ & $1.0 \mathrm{MPa} \sqrt{\mathrm{m}}_{\mathrm{m}}$ & 35 \\
\hline
\end{tabular}

Two failure criteria were employed to define the time of failure of a brick: 1) crack initiation, and 2) crack extension to 'near' control rod channel (CRC). Here 'near' is defined as having a distance less than $8 \mathrm{~mm}$ from the CRC. Failure of the 30 specimens was simulated and the failure probability $\left(\mathrm{P}_{\mathrm{f}}\right)$ of the graphite brick was evaluated as a function of time using Equation 6 below:

$P_{f}(t)=\frac{\text { Number of specimens failed up till time } t}{\text { Total number of specimens }}$

\section{Results and Discussion}

\subsection{UMAT Subroutine Verification}


The accuracy of the UMAT subroutine, developed for evaluating the stresses in the graphite brick subjected to in-reactor conditions, was established by comparing the numerically-predicted stresses with the stresses obtained from the analytical solution provided in [7] for a hypothetical cylindrical brick.

Figures 9 and 10 show the variation of the hoop and axial stresses, respectively, with time at the inner and outer surfaces of the cylindrical graphite brick. At the outer surface, both the hoop and axial stresses were initially compressive but gradually turned tensile later on and continued increasing thereafter. At the inner surface of the brick, the stresses followed the opposite trend, i.e., they were initially tensile and gradually turned compressive and continued increasing in magnitude. It can be seen that the numerical solution matched quite well with the analytical solution, with the two solutions only diverging after 20 years. The effects of changing the creep Poisson's ratio and creep level on the stresses were also assessed and found to be in good agreement with the analytical solution. Thus, the developed UMAT subroutine could predict the stresses in graphite bricks under irradiation with reasonable accuracy: with the error of 1-2 MPa at turnaround of stresses (10 years) and 7-9 MPa at the end of 30 years.

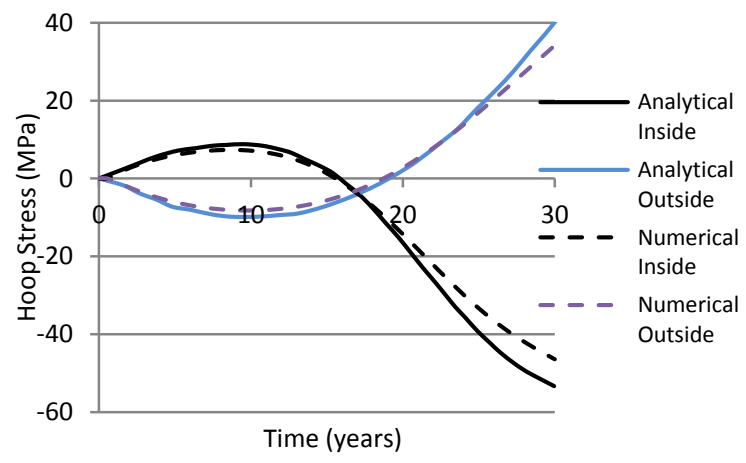

Figure 9: Variation of hoop stresses in the cylindrical graphite brick.

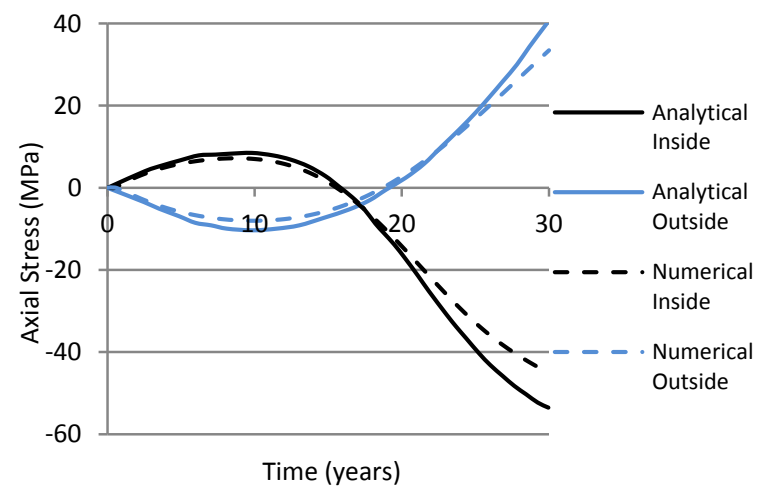

Figure 10: Variation of axial stresses in the cylindrical graphite brick.

\subsection{Results for ATR-2E Prismatic Reflector Brick}

The finite element model of the prismatic reflector brick was analyzed in Abaqus for each of the thirty sets of fracture toughness and strength values for ATR-2E graphite. Figure 11 shows the maximum principal stress distribution in the graphite brick at the end of 2, 4, 6, 8, 9.5 and 15.4 years for specimen 1 
$\left(\sigma_{\mathrm{f}}=13.7 \mathrm{MPa}, \mathrm{G}_{\mathrm{IC}}=100.5 \mathrm{~J} / \mathrm{m}^{2}\right)$. Figure 12 shows the variation of the maximum principal stress with time at two different locations in the reflector brick. With an increase in irradiation, the maximum principal stress at these two points increased until a crack initiated from one of the sides closest to the control rod channel. Element B, being nearer to the crack location, underwent significant stress relaxation. However, element A, being farther from the crack initiation site, underwent small stress relaxation. Thereafter, due to continued irradiation, there was increase in the stresses at both the locations until about 15-18 years, after which the stresses turned around and decreased continuously. It may be noted that the stress at element A becomes higher than the strength prescribed for this brick model (13.7 MPa). It indicates the possibility of cracking at multiple locations in the reflector brick.

Figure 11 shows the crack initiation and propagation through the reflector brick. It was found that the cracks initiated at the right lower edge of the specimen and propagated towards the control rod channel. Initiation of cracks from this particular location can be attributed to the high dose gradient present between the control rod channel and the brick edge (Fig. 7) which led to the development of high stresses in the region. Although a high dose gradient is present at the two right corners of the brick, they are geometrically unconstrained and therefore do not allow high stress development. The crack initiation location indicates that the outer surface of the reflector brick, which is in contact with a fuel brick, is more susceptible to failure than the inner free surfaces of the control rod channel. For some cases, the crack did not reach the control rod channel and stopped at a short distance of $\sim 8 \mathrm{~mm}$ before reaching it. So, the time to reach 'near' the control rod channel is reported herein instead of the time to reach the control rod channel. The inability of the cracks to reach the control rod channel can be explained on the basis of high compliance and stress relaxation developed in the structure due to cracking. For each specimen, the respective times at which the crack initiated and reached near the control rod channel were obtained and are listed in Table 2.

It was predicted that it took about 5-7 years for the first crack to reach near the control rod channel following crack initiation; in some cases (specimens numbered 3, 4, 14, 20), it took more than 15 years. The average duration for crack propagation was 9.4 years. In other cases $(6,7,12,16,18,21)$, multiple cracks initiated and got arrested without traversing significant distance in the brick. For quantitative analysis of numerical results, such specimens were considered to have not failed. For cases 15 and 20, numerical solution could not be obtained for the entire 30 years due to difficulties in obtaining convergence (see Table 2 for details). These two cases were not considered for failure probability evaluation based on the second criterion (criterion B) later on. 

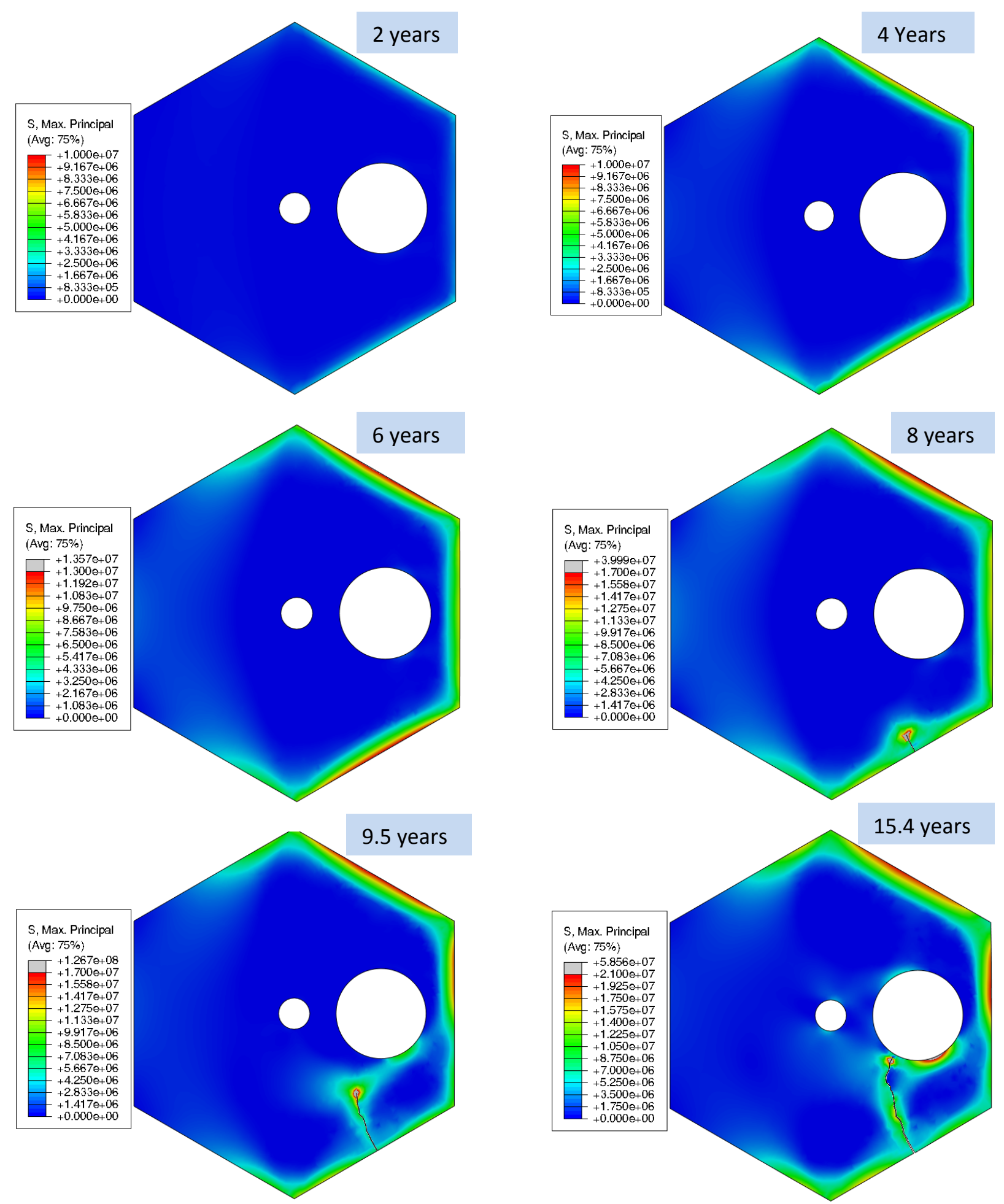

Figure 11: Distribution of the maximum principal stress in the reflector brick with ATR-2E graphite $\left(\sigma_{\mathrm{f}}=13.7 \mathrm{MPa}, \mathrm{G}_{\mathrm{IC}}=100.5\right.$ $\mathrm{J} / \mathrm{m}^{2}$ ) at the end of $2,4,6,8,9.5$ and 15.4 years. 


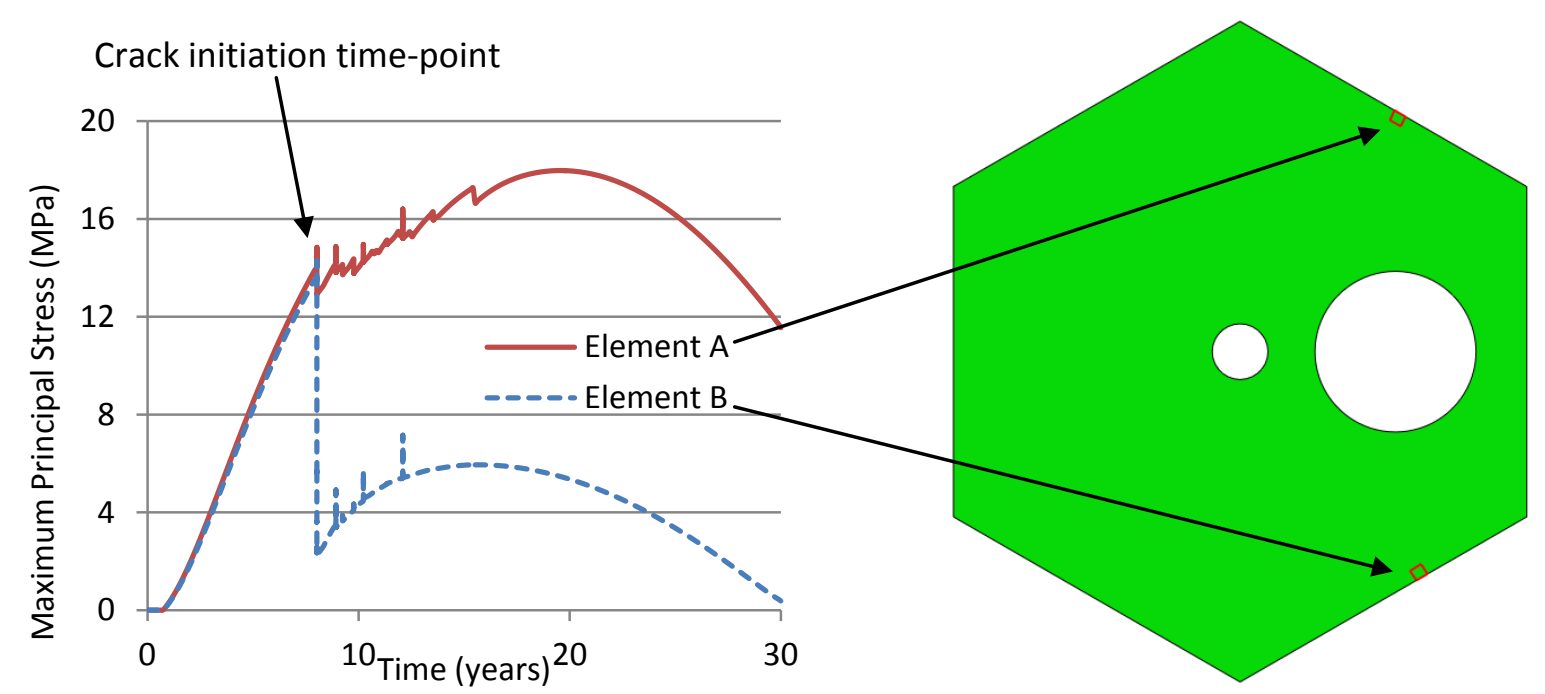

Figure 12: Variation of the maximum principal stress with time at the inner and outer surfaces of the brick for specimen $1\left(\sigma_{\mathrm{f}}=\right.$ 13.7 $\mathrm{MPa}, \mathrm{G}_{\mathrm{IC}}=100.5 \mathrm{~J} / \mathrm{m}^{2}$ ).

Figure 13 shows that the crack initiation time of the reflector brick specimens was governed mainly by their strength: bricks with higher strength began to crack later than bricks with lower strength. The brick specimen with the lowest strength of $8.7 \mathrm{MPa}$ began to crack at 5.2 years, while the brick with the greatest strength of $15.1 \mathrm{MPa}$ did so at 8.9 years.

Figure 14 shows that, with an increase in the strength, the time for the crack to reach a position near the control rod channel (CRC) is delayed if this happens prior to the turnaround of stresses $(<18$ years). If the CRC is reached after turnaround, the strength does not have an effect on the time to failure. Figure 15 shows that no significant correlation exists between the time taken for the crack to reach the $\mathrm{CRC}$ and the fracture toughness of the specimens for all cases.

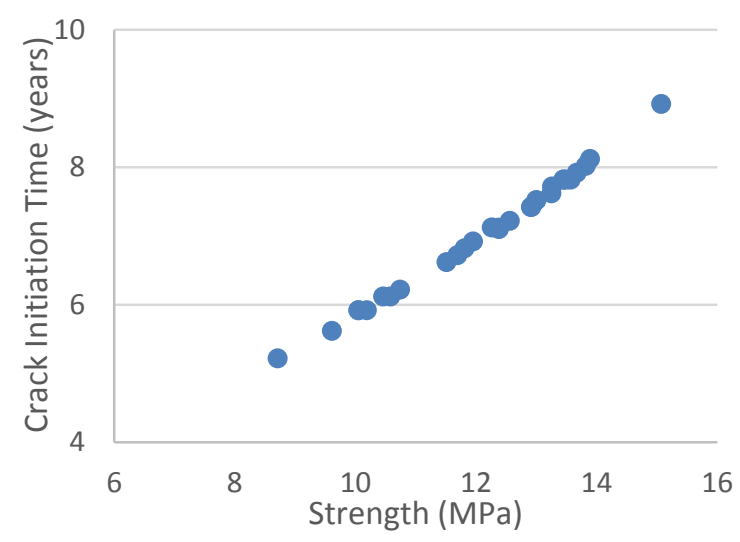

Figure 13: Crack initiation time vs strength of the specimen. 


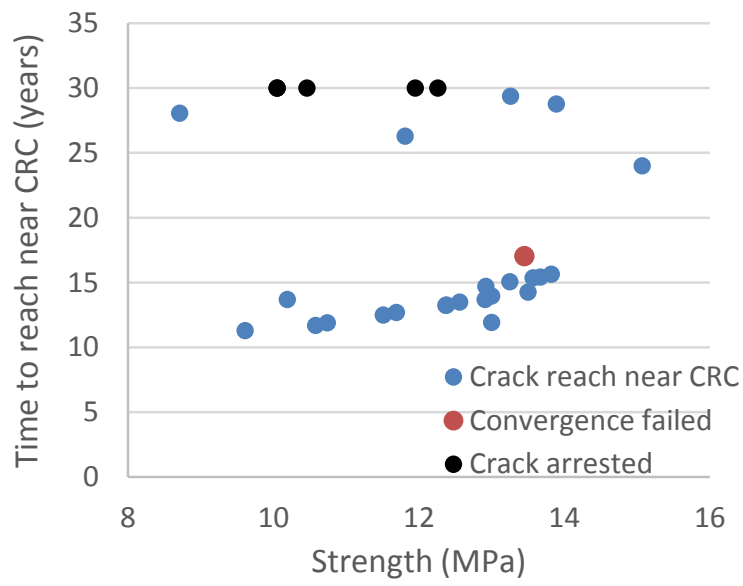

Figure 14: Time for the crack to reach near control rod channel (CRC) vs strength of the specimen.

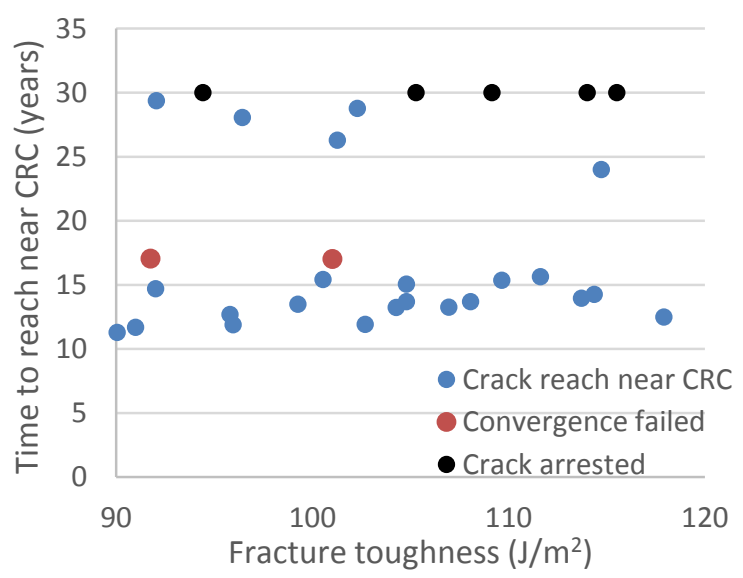

Figure 15: Time for the crack to reach near control rod channel (CRC) vs fracture toughness of the specimen.

Finally, the failure probability of the ATR-2E graphite brick as a function of time was obtained according to Equation (6) and based on the two criteria: (A) crack initiation and (B) crack extension to near control rod channel (CRC), as shown in Figure 16. Cases 15 and 20, for which solution for the entire 30 years could not be obtained due to difficulties in obtaining convergence, are excluded from the failure probability calculations based on criterion B. Predictions based on failure criterion A are much more conservative than the predictions based on failure criterion B.

With criterion A, no failure was predicted before year 5. Most reflector bricks failed during the period of 5-9 years. The steep rise in failure probability during this time range can be attributed to the rapid increase in the stress magnitude, as shown in Figure 12. After 8.9 years, the failure probability was almost equal to one.

The failure probability based on criterion B rises steeply during the period of 11 to 16 years. Thereafter, the proportion of failed bricks only rises gradually. In fact, between 16 and 24 years, no further failure was predicted. Beyond 24 years, the failure probability rises again, but only gradually. The failures predicted after 24 years are for those specimens in which the crack was arrested for some time but 
resumed propagation thereafter. The failure probability does not reach the value of one because in some specimens the crack did not resume propagation after traversing a short path, by which time the stress distribution had reached turnaround. Such specimens are considered to have not failed during the 30 years of operation of the reactor simulated.

The variation of the fracture energy and strength with irradiation was not considered in this study due to a lack of data. However, if the strength of ATR-2E graphite also increases with irradiation as for IG-110 [20] then the brick failure times are expected to be greater than those presented. Also, the 2D model used in this study means that the crack was considered to be propagating throughout the height of the brick. This is a conservative assumption. A three-dimensional fracture simulation may show more crack arrest. Finally, the U.K. creep law used in this study is known to diverge from the irradiation creep behavior of ATR-2E graphite at high neutron fluence, which will also affect the predictions, especially for cases where failure occurs after turnaround.

The explicit crack modeling approach presented herein has the potential to decrease the uncertainties and design margins associated with the existing approaches, and can contribute to the current development of the ASME codes for the design and construction of VHTR core components. However, more information, especially changes in the fracture properties of graphite with time and more representative creep data, is required to improve the accuracy of the predictions.

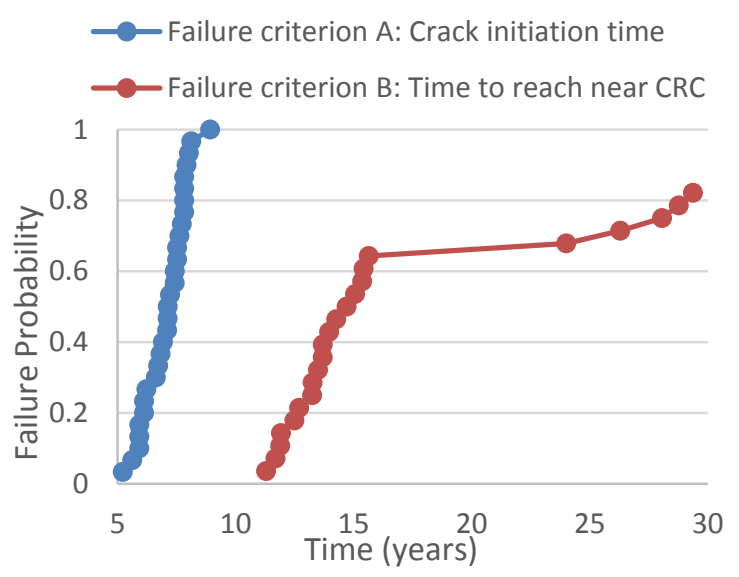

Figure 16: Failure probability of ATR-2E graphite brick vs. time based on two criteria; CRC: control rod channel. 
Table 2: The fracture toughness, strength, crack initiation time and time at which crack reaches near the control rod channel ( $\sim 8 \mathrm{~mm}$ distance from the channel).

\begin{tabular}{|c|c|c|c|c|}
\hline $\begin{array}{l}\text { Specimen } \\
\text { number }\end{array}$ & $\begin{array}{c}G_{I C} \\
\left(\mathrm{~J} / \mathrm{m}^{2}\right)\end{array}$ & $\begin{array}{c}\text { Strength } \\
\text { (MPa) }\end{array}$ & $\begin{array}{c}\text { Crack } \\
\text { initiatio } \\
\text { n time } \\
\text { (years) }\end{array}$ & $\begin{array}{c}\text { Time at } \\
\text { which crack } \\
\text { reaches near } \\
\text { channel } \\
\text { (years) }\end{array}$ \\
\hline 1 & 100.54 & 13.67 & 7.92 & 15.42 \\
\hline 2 & 96.43 & 8.71 & 5.22 & 28.06 \\
\hline 3 & 114.72 & 15.07 & 8.92 & 24.00 \\
\hline 4 & 95.96 & 10.74 & 6.22 & 11.89 \\
\hline 5 & 105.28 & 10.46 & 6.12 & $\mathrm{~N} / \mathrm{A}$ \\
\hline 6 & 115.51 & 10.05 & 5.92 & $\mathrm{~N} / \mathrm{A}$ \\
\hline 7 & 111.62 & 13.82 & 8.02 & 15.64 \\
\hline 8 & 106.95 & 12.38 & 7.1 & 13.26 \\
\hline 9 & 92.01 & 12.92 & 7.424 & 14.7 \\
\hline 10 & 90.99 & 10.58 & 6.12 & 11.69 \\
\hline 11 & 114.00 & 12.26 & 7.124 & $\mathrm{~N} / \mathrm{A}$ \\
\hline 12 & 90.05 & 9.61 & 5.62 & 11.29 \\
\hline 13 & 92.05 & 13.26 & 7.72 & 29.37 \\
\hline 14 & 108.06 & 12.91 & 7.42 & 13.69 \\
\hline 15 & 101.02 & 13.45 & 7.82 & $17.02 *$ \\
\hline 16 & 114.36 & 13.50 & 7.82 & 14.26 \\
\hline 17 & 109.15 & 10.05 & 5.92 & $\mathrm{~N} / \mathrm{A}$ \\
\hline 18 & 95.80 & 11.69 & 6.72 & 12.69 \\
\hline 19 & 101.27 & 11.81 & 6.82 & 26.29 \\
\hline 20 & 91.75 & 13.45 & 7.82 & $17.05^{*}$ \\
\hline 21 & 104.79 & 10.19 & 5.92 & 13.69 \\
\hline 22 & 117.91 & 11.51 & 6.62 & 12.49 \\
\hline 23 & 99.26 & 12.56 & 7.22 & 13.49 \\
\hline 24 & 94.42 & 11.95 & 6.92 & $\mathrm{~N} / \mathrm{A}$ \\
\hline 25 & 104.27 & 12.37 & 7.12 & 13.24 \\
\hline 26 & 102.29 & 13.89 & 8.12 & 28.77 \\
\hline 27 & 102.69 & 13.00 & 7.52 & 11.92 \\
\hline 28 & 109.65 & 13.57 & 7.82 & 15.36 \\
\hline 29 & 104.79 & 13.25 & 7.62 & 15.06 \\
\hline 30 & 113.71 & 13.00 & 7.52 & 13.96 \\
\hline
\end{tabular}

N/A: Cases for which crack was arrested and did not reach control rod channel.

* Numerical solution failed to converge after this time.

\section{Conclusions}

The integration of the user-defined subroutine UMAT with the numerical technique XFEM for modeling cracking on a common computational platform allows irradiation-induced failure of VHTR graphite components under in-reactor conditions to be modeled explicitly.

The results indicate that the criterion chosen for defining failure strongly affects the failure probability predictions. It was found that cracking initiated from one of the sides closest to the control rod channel (CRC) but breaching of the CRC could be significantly delayed through crack arrest. 


\section{Acknowledgement}

The financial support from DOE Office of Nuclear Energy's Nuclear Energy University Programs and the computing facilities by Minnesota Supercomputing Institute are gratefully acknowledged.

\section{References}

1. A Technology Roadmap for Generation IV Nuclear Energy Systems, U.S. DOE Nuclear Energy Research Advisory Committee and the Generation IV International Forum, 03-GA50034, December 2002.

2. J.H.W. Simmons, Radiation Damage in Graphite: International Series of Monographs in Nuclear Energy, 102, Elsevier, 2013.

3. T. Oku and M. Ishihara, Lifetime evaluation of graphite components for HTGRs, Nuclear Engineering and Design, 227, 209-217, 2004.

4. S. Yu, H. Li, C. Wang and Z. Zhang, Probability assessment of graphite brick in the HTR - 10, Nuclear Engineering and Design, 227, $133-142,2004$.

5. W. Weibull, A Statistical Theory of the Strength of Materials, Proc. Royal Swedish Academy of Eng. Sci., 151, 1-45, 1939.

6. W. Weibull, A Statistical Distribution Function of Wide Applicability, Journal of Applied Mechanics, 18, 293-297, 1951.

7. H. Li, A. Fok, B. J. Marsden, An Analytical Study on the Irradiation - Induced Stresses in Nuclear Graphite Moderator Bricks, Journal of Nuclear Materials, 372, $164-170,2008$.

8. Z. Zou, S. L. Fok, B. J. Marsden and S. O. Oyadiji, Numerical Simulation of Strength Test on Graphite Moderator Bricks Using a Continuum Damage Mechanics Model, Engineering Fracture Mechanics, 73, 318-330, 2006.

9. Abaqus Documentation, Dassault Systemes Simulia Corp., Providence, RI, USA.

10. D. K. L. Tsang and B. J. Marsden, The Development of a Stress Analysis Code for Nuclear Graphite Components in GasCooled Reactors, Journal of Nuclear Materials, 350, 208-220, 2006.

11. S. Mohanty, R. Jain, S. Majumdar, T. J. Tautges and M. Srinivasan, Coupled Field Structural Analysis of HTGR Fuel Brick Using Abaqus, Proceedings of ICAPP 2012, Paper \# 12352, Chicago, USA, June 24-28, 2012.

12. B.C. Mitchell, J. Smart, S.L. Fok and B.J. Marsden, The Mechanical Testing of Nuclear Graphite, Journal of Nuclear Materials, 322, 126-137, 2003.

13. G. Singh, H. Li, A. Fok and S. Mantell, Size Effect on the Fracture Properties of Nuclear Graphite, Graphite Testing for Nuclear Applications, STP 1578, 1-19, doi:10.1520/STP157820130125, ASTM International, West Conshohocken, PA, 2014.

14. G. Haag, Properties of ATR-2E Graphite and Property Changes Due to Fast Neutron Irradiation, Institute for Safety Research and Reactor Technology, 2005.

15. R. L. Bratton, Modeling Mechanical Behavior of a Prismatic Replaceable Reflector Block, Idaho National Laboratory, Next Generation Nuclear Plant Project, INL/EXT-09-15868, 2009. 
16. R. J. Price, Irradiation-Induced Creep in Graphite: A Review, GA-A16402, Project 7400, General Atomic Company, August, 1981.

17. T. Belytschko and T. Black, Elastic Crack Growth in Finite Elements with Minimal Remeshing, International Journal for Numerical Methods in Engineering, 45, 601-620, 1999.

18. J. Melenk, I. Babuska, The Partition of Unity Finite Element Method: Basic Theory and Applications, Computer Methods in Applied Mechanics and Engineering, 39, 289-314, 1996.

19. Department of Energy (DOE), Evaluation of Graphite Stresses, Reliability and Life (Internals), DOE/HTGR-86-058, June, 1986.

20. S. Ishiyama, T.D. Burchell, J.P. Strizak and M. Eto, The effect of high fluence neutron irradiation on the properties of a finegrained isotropic nuclear graphite, Journal of Nuclear Materials, 230, 1-7, 1996. 